\title{
Article \\ Effect of Spatial Variation of Earthquake Ground Motions on Seismic Vulnerability of Urban Road Network Considering Building Environment
}

Ding Wang ${ }^{1,2, * \mathbb{D}}$, Xinyu Zhao ${ }^{1}$ and Yue Liu ${ }^{1,3}$

1 School of Civil Engineering \& Mechanics, Yanshan University, Qinhuangdao 066004, China; zxy924147079@163.com (X.Z.); liuyue360307350@163.com (Y.L.)

2 Key Laboratory of Green Construction and Intelligent Maintenance for Civil Engineering of Hebei Province, Yanshan University, Qinhuangdao 066004, China

3 Beijing Building Construction Research Institute Co., Ltd., Beijing 100039, China

* Correspondence: wangding@ysu.edu.cn; Tel.: +86-180-3356-1736

check for

updates

Citation: Wang, D.; Zhao, X.; Liu, Y.

Effect of Spatial Variation of

Earthquake Ground Motions on

Seismic Vulnerability of Urban Road

Network Considering Building

Environment. Buildings 2022, 12, 308.

https://doi.org/10.3390/

buildings12030308

Academic Editor: Marco Di

Ludovico

Received: 7 February 2022

Accepted: 3 March 2022

Published: 5 March 2022

Publisher's Note: MDPI stays neutral with regard to jurisdictional claims in published maps and institutional affiliations.

Copyright: (c) 2022 by the authors Licensee MDPI, Basel, Switzerland. This article is an open access article distributed under the terms and conditions of the Creative Commons Attribution (CC BY) license (https:/ / creativecommons.org/licenses/by/ $4.0 /)$.

\begin{abstract}
Evaluating the seismic damage of urban road infrastructure systems is of vital importance in reducing the earthquake hazard risk of cities. Urban road infrastructure systems are commonly represented as a spatial network that covers the whole city, and in its seismic damage analysis the spatial variation of earthquake ground motions cannot be ignored. However, the effect of the spatial variation of ground motions on the seismic vulnerability of urban road networks is unknown. In this article, based on the case study on Datong, China, it is shown that the spatially variation of ground motions may increase the damage risk of urban road networks and should be considered in the seismic vulnerability analysis. This was achieved by developing a method to evaluate the performance of a post-earthquake road network considering the structural damage of road components and the building environment. This work is anticipated to be a starting point for more sophisticated studies on the earthquake risk analysis of spatially extended urban lifeline systems.
\end{abstract}

Keywords: urban road network; seismic ground motion; seismic vulnerability; building environment

\section{Introduction}

Extreme earthquakes may cause serious economic losses and causalities in cities. Earthquake experience indicates that the damage of urban road infrastructure will reduce the efficiency of the emergency rescue and relief material transportation after large earthquakes [1-3]. The urban road infrastructure system is commonly represented as a spatial network and connects almost all areas of the city. For seismic analysis of long-span structures and lifeline systems, due to the attenuation and dispersion effects of earthquake wave propagation, the ground motions at the engineering surface are inconsistent and spatially variable [4]. Hence, the spatial variation of seismic ground motions cannot be ignored in the vulnerability evaluation of urban road networks. However, the effect of the spatial variation of ground motion on the damage state of post-earthquake road networks is still unknown.

Urban road networks are composed of road components, e.g., road pavement, embankments, bridges, tunnels, and retaining walls. Previous studies on the seismic vulnerability of urban road networks have usually focused on evaluating the damage state and fragility of road infrastructure at the component and systemic levels.

At the component level, studies focus on the evaluation of the seismic fragility function of road components and the area of building collapse debris due to an earthquake. Lagaros et al. proposed an analytical fragility function for road embankments based on the neural network model [5]. Maruyama et al. presented a fragility curve for embankments from the investigation and statistical analysis of four large earthquakes in Japan [6]. Liao developed 
an empirical fragility function of road sections considering the structure damage of road components and the building collapse debris and obtained the values of the parameters from the damage investigation in the 2008 Wenchuan earthquake [7]. Argyroudis and Kaynia proposed the fragility functions for embankments and slopes using a numerical method [8]. The debris from building collapse will block the road sections under large earthquakes, especially in the urban historical centers. Goretti and Sarli developed a linear distribution model of building collapse to evaluate the blockage probability of road sections [9]. Safe evaluation and damage classification of existing buildings are important for predicting the building collapse due to earthquakes and can be achieved using soft computing techniques [10]. The seismic vulnerability of the buildings is also necessary for computing the blockage probability of road sections due to building debris [11].

At the systemic level, several methods have been proposed to assess the seismic vulnerability of the entire urban road network. Argyroudis et al. developed a framework to analyze the seismic risk of urban road systems considering the building collapse debris [12]. Zanini et al. presented an approach to evaluate the functionality of post-earthquake urban road networks [13]. Aydin et al. used the size of the pieces to measure the resilience of a road network after an earthquake based on the theory of complex networks [14]. Capacci, Biondini, and Titi presented a method to evaluate the vulnerability and resilience of road networks considering the seismic damage of aging bridges [15]. Zhou, Wang, and Sheu analyzed the global connectivity and local connectivity of the regional road network using the analytical solution of the percolation on random networks [16]. Huang and Tang proposed a Bayesian network approach to assess the seismic vulnerability of urban road networks [17]. Anelli, Mori, and Vona developed an approach to estimate the blockage probability of a road section considering the building debris due to a large earthquake [18]. Costa et al. presented the open tools to evaluate the effect of earthquake damage on road traffic [19]. El-Maissi, Argyroudis, and Nazri summarized the methods for assessing the seismic vulnerability of road networks [20]. Wang et al. used the number of pieces and the diameter of the maximal piece to describe the performance of post-earthquake road networks and presented a framework to calculate the seismic fragility curve of the urban road system as a whole [21].

As mentioned above, the road network covers almost all the areas in city and the influence of the spatial variation of ground motions cannot be ignored [4,22]. However, in the previous studies the intensity of seismic ground motions is usually assumed to be consistent. In addition, the connectivity is thought to be the most important criterion to determine the damage state of post-earthquake road networks. The road network which loses connectivity will be identified as being completely damaged in the previous studies. However, in the disconnected road networks there is a high probability that a large piece exists and connects most of the nodes in the original network. In this situation, the serviceability of the road network is still partly retained.

Hence, based on the case study on Datong, China, this article focuses on how the spatial variation of seismic ground motions affects the vulnerability of urban road networks. Besides the connectivity, the existence of large pieces is also considered as an index for determining the performance of post-earthquake road networks in this work. Figure 1 presents a flowchart to show the main steps of the seismic vulnerability evaluation of road networks in this article. The implementation of this flowchart will be introduced in the next section. 


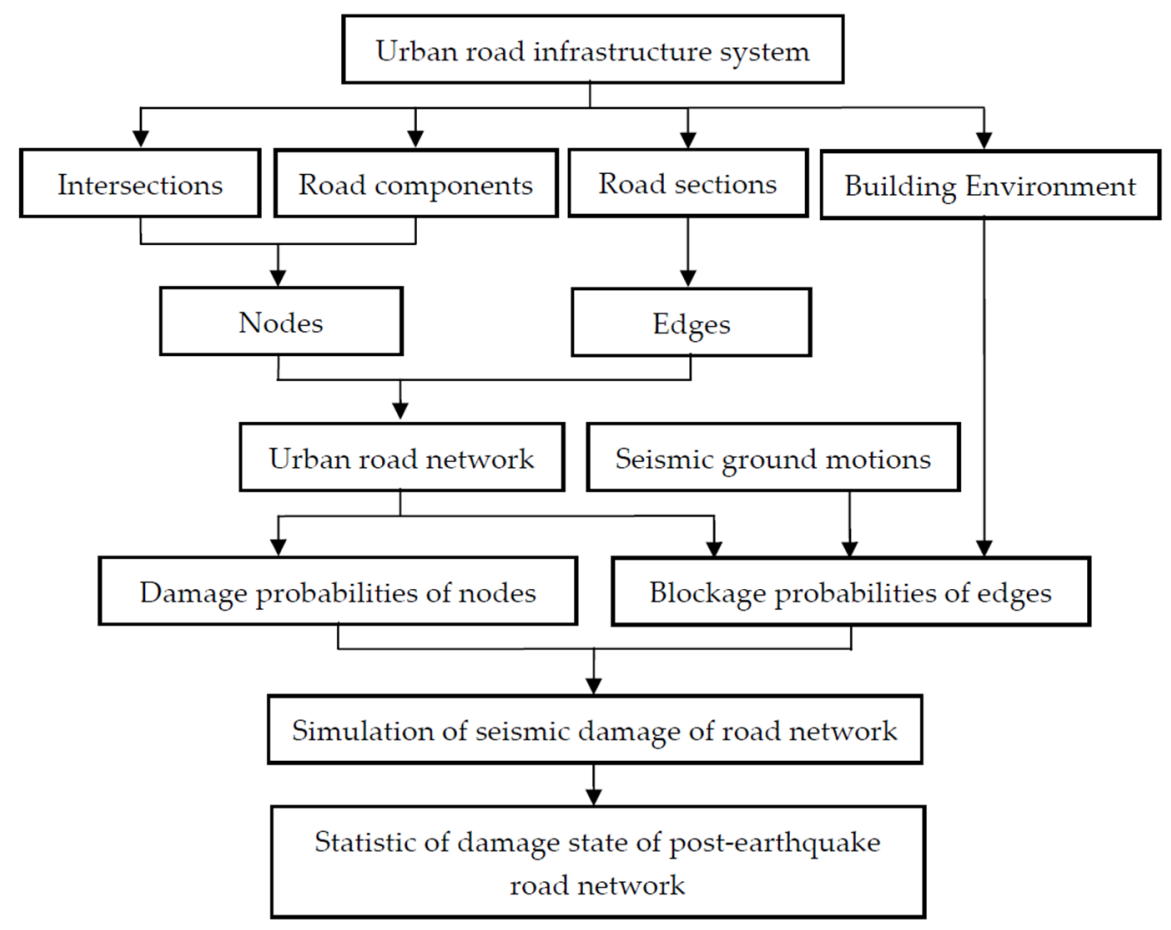

Figure 1. Flowchart of the method used here to evaluate the seismic vulnerability of urban road networks.

\section{Seismic Vulnerability Analysis of an Urban Road Network}

\subsection{Network Modeling}

Urban road infrastructure systems are composed of different types of road components, including road pavements, bridges, tunnels, embankments, cutting, slopes, and retaining walls. The seismic damage of urban road infrastructure could be classified as direct damage, which is the structural damage of the road components due to strong ground shake, and indirect damage, which is caused by the damage of other infrastructure, e.g., the building collapse debris.

Urban road infrastructure systems could be simplified as spatial networks [23]. Commonly, in the road network, the nodes are the intersections and the edges are the road sections between the intersections. As mentioned above, bridges, tunnels, slopes, and retaining walls are vulnerable to seismic shaking or ground failures due to geotechnical hazards in large earthquakes. Therefore, the distribution of the vulnerable components in the road network should be considered for the seismic vulnerability assessment. Here, the vulnerable road components are also modeled as nodes in the road network. Figure 2 shows the illustration of the road network modeling. As shown by Figure $2 \mathrm{a}$, there is a river through the city with seven bridges on it. In the road network presented by Figure $2 b$, these seven bridges are modeled as nodes. The intersections are also modeled as nodes. The edges in the road network are the road sections between the nodes.

\subsection{Simulation of Spatially Variable Seismic Ground Motions}

Because of the large span of an urban road network, the spatial variation of seismic ground motions must be considered for engineering purposes. Due to the source rupture and the seismic wave propagation, the ground motions at different ground positions have correlated amplitudes and phases [24]. Physically, the spatial variation of ground motions is divided into three categories, namely the wave passage effect, the coherency effect, and the local stie effect. The variation of the rock depth also affects the seismic wave propagation and causes the change of the shape of the ground motion time history [25]. In earthquake engineering, the spatial variation of nonstationary ground motions is described by the evolutionary power spectral density (EPSD) and the coherency function of the ground 
motion field. Several parametric models of the seismic EPSD and coherency function are proposed to reflect the spatial variation of ground motions.

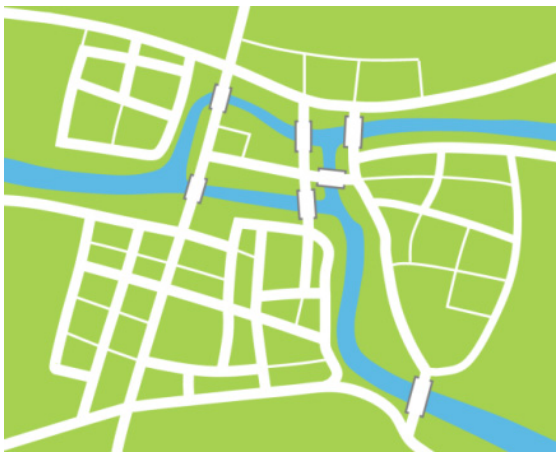

(a)

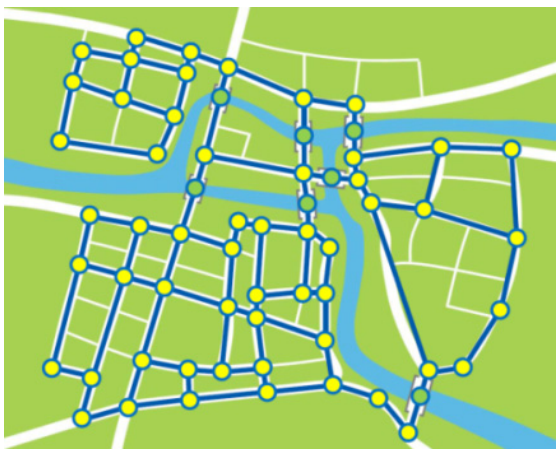

(b)

Figure 2. Illustration of the network modeling of urban roads: (a) urban area and (b) road network.

Combining with the EPSD and coherency function models, the spectral representation method is widely used to simulate spatially variable ground motions [26,27]. Let $H_{j r}\left(\omega_{s}, t\right)$ denote the elements of the Cholesky decomposition of the EPSD matrix. The formula for simulating spatial variable seismic ground motions is:

$$
h_{j}(t)=2 \cdot \sum_{r=1}^{m} \sum_{s=1}^{N_{f}}\left|H_{j r}\left(\omega_{s}, t\right)\right| \cdot \sqrt{\Delta \omega} \cdot \cos \left[\omega_{s} \cdot t-\vartheta\left(\omega_{s}, t\right)+\varphi_{r s}\right]
$$

in which $m$ is the number of the ground motions, $N_{f}$ is the number of the frequency components, $\omega_{s}=s \cdot \Delta \omega, s=1,2, \ldots, N, \Delta \omega=\omega_{c} / N$ is the frequency bandwidth, $\omega_{c}$ is the upper cut-off frequency, $\vartheta_{j r}(\omega, t)$ is the phase angle of $H_{j r}\left(\omega_{s}, t\right)$ as:

$$
\vartheta_{j r}(\omega, t)=\tan ^{-1}\left(\frac{\operatorname{Im}\left[H_{j r}(\omega, t)\right]}{\operatorname{Re}\left[H_{j r}(\omega, t)\right]}\right)
$$

In which $\operatorname{Im}[\cdot]$ and $\operatorname{Re}[\cdot]$ denote the imaginary part and real part of complex number, respectively. $\varphi_{r s}$ are the random phase angles distributed uniformly in the frequency interval $[0,2 \pi]$.

To simulate the spatially variable ground motions, the EPSD and coherency models should be designated. In this article, the EPSD model proposed by Wang et al. [28] and the coherency model proposed by Wang et al. [29] are used to generate the samples of spatially variable ground motions. Other models of the EPSD [30-33] and coherency [34-37] are also available within this approach.

In this article, the horizontal components of the spatially variable ground motions are generated. In fact, many earthquakes have been characterized by major mainshocks in the vertical direction and their vertical components are stronger than the horizontal ones. The spectral representation method is also available for the vertical components by using the EPSD and coherency models of vertical ground motions.

\subsection{Performance Evaluation of Post-Earthquake Road Network}

Due to the seismic damage of road components and the debris of the buildings beside roads, the road sections may be blocked and the topology of the road network will be changed after a large earthquake. Considering the randomness of earthquake intensity, seismic resistance capacity of road components, and building collapse, the blockage of a road section is a random event and should be described by random variables.

For evaluating the vulnerability of urban road systems, the damage state of a road network must be defined first. Figure 3 shows four typical performances of the post-earthquake road networks in Figure 2. If the earthquake intensity is small, the road components and 
buildings are safe. In this situation, all the nodes and edges are undamaged, and the network is complete, as shown in Figure 3a. The serviceability of the road network is completely retained. The red path in Figure $3 a$ is the diameter of the network. With the earthquake intensity increasing, a small number of road components or buildings may be damaged, and the corresponding edges will become blocked and impassable. If one or more edges in the diameter path of the original network are damaged, the diameter of the post-earthquake network will become larger, as shown by the red line in Figure $3 b$. In this case, the post-earthquake road network is connected, but the distances between the nodes increase, which means the traffic capacity of the entire road network decreases. Further increase in the earthquake intensity will cause more road components and buildings damaged in the earthquake. With the number of the blocked road sections increasing, the post-earthquake road network may be broken into two or more pieces and lose its connectivity, as presented by Figure 3c. In the previous studies, the road network is usually thought to lose the transportation capacity completely when it is disconnected. However, it is a high probability that there is still a large piece connecting most of the nodes in the network. This large piece makes a high proportion of nodes connected and accessible, and the transportation capacity of the network is partly maintained. When the earthquake intensity is so high that a large number of nodes and edges are damaged, the road network will be broken into several small pieces, as shown in Figure 3d. The sizes of the pieces are all small. For this situation, the post-earthquake road network is thought to be fragmented and loses its serviceability totally.

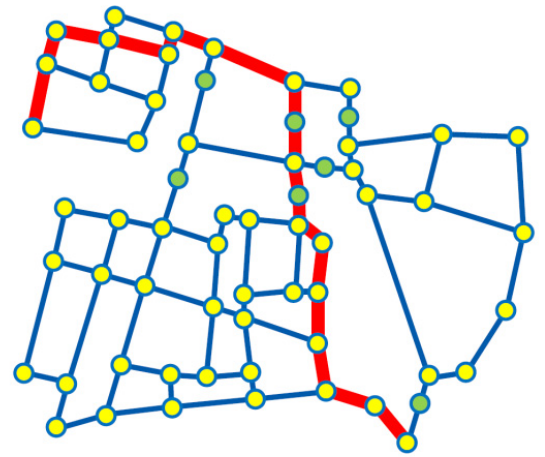

(a)

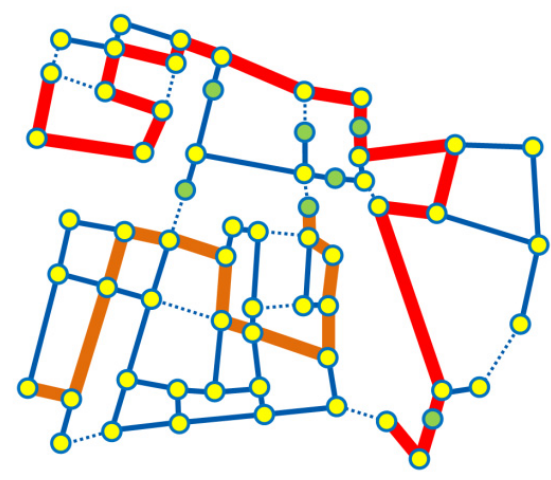

(c)

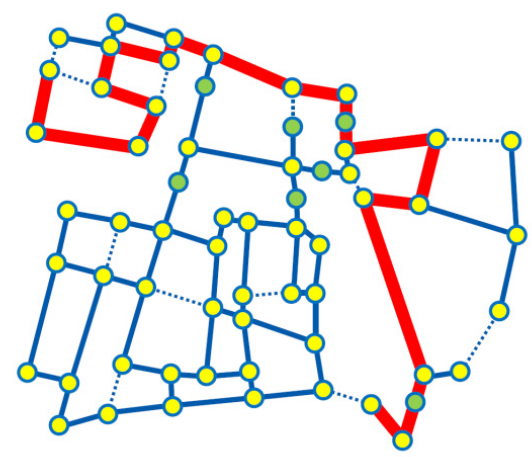

(b)

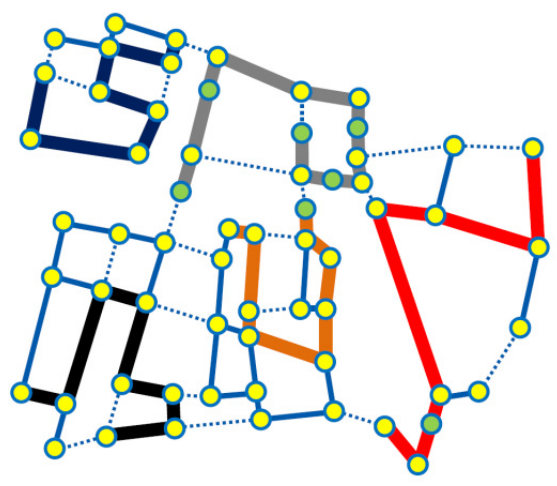

(d)

Figure 3. Illustration of the damage states of a road network: (a) original network, (b) connected postearthquake network, (c) disconnected post-earthquake network with large piece, and (d) fragmented post-earthquake network.

For measuring the seismic performance of the post-earthquake road network described above, in this article five damage states, namely undamaged, minor, moderate, extensive, and complete, are defined. The details of these five damage states are listed in Table 1. It is emphasized that, in this work, the disconnected road network is also considered to 
have partly transport capacity if there is a large piece in the post-earthquake network. This damage state is defined as an extensive but not complete damage state. For the complete damage state, the road network is fragmented and has no large piece.

Table 1. Description of the damage states of the post-earthquake network.

\begin{tabular}{|c|c|}
\hline Damage State & Description \\
\hline Undamaged & $\begin{array}{l}\text { All the nodes and edges are safe during the earthquake. The serviceability of } \\
\text { the network is totally maintained. }\end{array}$ \\
\hline Minor & $\begin{array}{l}\text { Just a small proportion of nodes or edges are damaged. The post-earthquake } \\
\text { network is connected. The diameter of the network is not changed. The } \\
\text { earthquake has little influence on the serviceability of road network. }\end{array}$ \\
\hline Moderate & $\begin{array}{l}\text { The network is connected but a certain proportion of nodes and edges are } \\
\text { damaged. The diameter of the network becomes larger. The serviceability of } \\
\text { the network is affected significantly by the earthquake. }\end{array}$ \\
\hline Extensive & $\begin{array}{l}\text { The network is disconnected. There are one or more large pieces in the } \\
\text { post-earthquake network. The serviceability of the network decreases } \\
\text { significantly but is partly kept because of the existence of the large piece. }\end{array}$ \\
\hline Complete & $\begin{array}{l}\text { The network is broken into several small pieces. The serviceability of the } \\
\text { network is lost completely. }\end{array}$ \\
\hline
\end{tabular}

For measuring the damage states of the post-earthquake road network listed in Table 1 quantitatively, four performance indexes are defined and used here, namely the damage ratio of edges, piece number, the number of nodes in the maximum piece, and the diameter of the maximum piece.

The damage ratio of edges, denoted as $\rho_{E}$, is defined as:

$$
\rho_{E}=\frac{N_{D E}}{N}
$$

in which $N_{D E}$ is the number of the damaged edges during earthquake and $N$ is the total number of the edge in the original network. $\rho_{E}$ is used to measure the damage of the entire road network.

The piece number, $N_{C}$, is introduced to reflect whether the post-earthquake road network is connected. When the road network is connected, there is just one piece and $N_{C}=1$. If $N_{C}>1$, the network is broken into several pieces and becomes disconnected.

The number of nodes in the maximum piece and the diameter of the maximum piece, which are respectively denoted as $\rho_{C N}$ and $\rho_{C D}$, are used to measure the size of the maximal piece and determine whether there is a large piece in the post-earthquake network. In this article, $\rho_{C N}$ and $\rho_{C D}$ are both normalized. The number of nodes in the maximum piece $\rho_{C N}$ is defined as:

$$
\rho_{C N}=\frac{M_{C}}{M}
$$

in which $M_{C}$ is the number of nodes included in the maximum piece in the post-earthquake network and $M$ is the total number of nodes in the original network. If the post-earthquake network is connected, there is just one piece and $\rho_{C N}=1$, otherwise $\rho_{C N}<1$.

The diameter of the maximum piece $\rho_{C D}$ is defined as:

$$
\rho_{C D}=\frac{D_{C}}{D}
$$

in which $D_{C}$ is the length of the diameter of the maximum piece and $D$ is the diameter of the original network. As discussed above, when the road network is connected but several road sections are blocked, $\rho_{C D}$ will increase. In this situation, $\rho_{C D} \geq 1$. For high earthquake intensity, the road network is disconnected and $\rho_{C D}$ will decrease from its peak 
value because the network is broken into small pieces. Hence, with the earthquake intensity increasing, $\rho_{C D}$ increases first and then decreases.

Using $\rho_{E}, N_{C}, \rho_{C N}$, and $\rho_{C D}$, the damage states of the post-earthquake network in Table 1 could be measured quantitatively as shown in Table 2. For the undamaged state, all the road sections are passable and the road network is connected, which means $N_{C}=1$ and $\rho_{E}=0$. For the minor and moderate damage states, the road network is still connected but several edges are damaged. In this article, the threshold of $\rho_{E}$ is valued as 0.05 to distinguish the minor and moderate damage states. With the earthquake intensity increasing, the road network losses its connectivity and $N_{C}>1$, and the extensive and complete damage states will appear. The criterion to distinguish the extensive and complete damage states is whether there is a large piece in the post-earthquake road network. Here, the large piece is defined as the piece that includes at least $80 \%$ of the nodes and has a diameter path longer than that of the original network. Hence, for extensive damage state, $\rho_{C N} \geq 0.8$ and $\rho_{C D}>1$. Otherwise, the post-earthquake road network is in the complete damage state.

Table 2. Measurement of the damage states of the post-earthquake road network using the four performance indexes.

\begin{tabular}{cc}
\hline Damage State & Value Range of Performance Indexes \\
\hline Undamaged & $N_{C}=1, \rho_{E}=0$ \\
Minor & $N_{C}=1,0<\rho_{E}<0.05$ \\
Moderate & $N_{C}=1, \rho_{E} \geq 0.05$ \\
Extensive & $N_{C}>1, \rho_{C N} \geq 0.8, \rho_{C D}>1$ \\
Complete & $N_{C}>1, \rho_{C N}<0.8, \rho_{C D}>1$ \\
& or $N_{C}>1, \rho_{C D} \leq 1$ \\
\hline
\end{tabular}

\subsection{Seismic Damage Simulation and Vulnerability Analysis}

As mentioned above, the earthquake intensity, seismic resistance capacity of road components, and building collapse debris are random. Hence, the damage of the nodes and edges in earthquake is uncertain and should be described by random variables.

The damage of the nodes corresponds to the structural failure of vulnerability road components, especially the bridges in urban regions. Let $P_{f, i i}$ denote the damage probability of the node $i . P_{f, i i}$ equals the fragility function of the road components and could be determined according to the Hazus program [38]. The fragility function is defined as the proceeding probability of a particular damage state and is widely used in the seismic evaluation of engineering structures [39-41].

The damage of the edges corresponds to the blockage of road sections caused by the building collapse debris. Let $P_{f, i j}$ denote the damage probability of the edge connecting the nodes $i$ and $j . P_{f, i j}$ could be determined by the empirical and analytical methods. For the empirical method, the building collapse debris is treated as a random accident which will block the road sections and its occurrence probability is obtained by the investigation and statistical analysis in the earthquake-hit zone. For the analytical method, the debris area is evaluated according to the structural type, height, width, and seismic fragility curve of the building. The blockage probability is calculated considering the distribution of the buildings along the road and their fragility curves $[12,18]$.

In fact, $P_{f, i i}$ and $P_{f, i j}$ are both functions of earthquake intensity. By calculating the earthquake intensities of the spatially variable seismic ground motions generated in Section 2.2, the values of $P_{f, i i}$ and $P_{f, i j}$ corresponding to all the nodes and edges could be obtained.

The damage of the nodes and edges will change the topology structure of the road network. The topology structure of road network is presented by an adjacency matrix. The adjacency matrix, $\mathbf{A}$, is defined as:

$$
[\mathbf{A}]_{i j}= \begin{cases}1 & \text { if nodes } i \text { and } j \text { are connected } \\ 0 & \text { otherwise }\end{cases}
$$


in which $[\cdot]_{i j}$ denotes the $i j$ th entry of the matrix.

For determining the topology structure of the post-earthquake road network, a matrix $\mathbf{T}$ is introduced as:

$$
[\mathbf{T}]_{i j}=\left\{\begin{array}{cc}
1 & \text { if the edge between nodes } i \text { and } j \text { are passable after earthquake } \\
0 & \text { otherwise }
\end{array}\right.
$$

It should be noted that, due to the randomness of the blockage of road sections, the elements of $\mathbf{T}$ are random variables, the probability distributions of which are dependent on $P_{f, i i}$ and $P_{f, i j}$. Letting $\mathbf{A}^{\prime}$ post-earthquake road network, the elements of $\mathbf{A}^{\prime}$ are also random variables and could be expressed as:

$$
[\mathbf{A} /]_{i j}=[\mathbf{A}]_{i j} \cdot[\mathbf{T}]_{i j}
$$

The four performance indexes, $\rho_{E}, N_{C}, \rho_{C N}$, and $\rho_{C D}$, could be all calculated from $\mathbf{A}^{\prime}$. However, because the road network is not regular, these four performance indexes cannot be expressed analytically and their statistic characteristics are hardly obtained. An effective approach to solve this problem is the Monte Carlo method. By repeated sampling technology, a large number of samples of $\mathbf{T}$ are generated and the corresponding samples of $\mathbf{A}^{\prime}$ are obtained by Equation (8). Further, the values of $\rho_{E}, N_{C}, \rho_{C N}$, and $\rho_{C D}$ of each sample could be obtained and its damage state is determined according to Table 2 . The proportion of the samples in a particular damage state gives an approximation of the occurrence probability of this damage state and is a quantitative measure of the vulnerability of the post-earthquake road network.

\section{Effect of Spatial Variation of Seismic Ground Motions}

In this section, a case study on Datong, Shanxi Province, China is given to present the effect of the spatial variation of seismic ground motions on the vulnerability evaluation of an urban road network.

\subsection{Road Network Model of Datong}

Datong, the second-largest city in Shanxi Province, is located in the strong seismicity belt in the east of China. In Datong's history, there have been several large earthquakes. For example, the Datong-Yanggao Earthquake in 1989 was the biggest earthquake in North China since the 1976 Tangshan earthquake. Therefore, it is of practical significance to analyze the seismic vulnerability of the road network in Datong, which could provide valuable reference for future urban planning.

Figure 4 presents the urban road network of Datong. The locations of the nodes and edges are from the Baidu Map database (https:/ /map.baidu.com, accessed on 6 February 2022). There is a river through the middle of the city. In this road network, the roads with four or more lanes are selected and modeled as edges. The number of the nodes in the road network is 211, in which the nodes 1-206 are the intersections and the nodes 207-211 are the bridges. From Figure 4, it can be found that the roads in the central and western areas are distributed densely, and their lengths are smaller than those in the eastern area. The bridges in the road network are all located in the central area. The characteristics of the road network in Datong are shown in Table 3. The classification of the bridges is determined by the field investigation according to the Hazus Program [38] and shown in Table 4. 


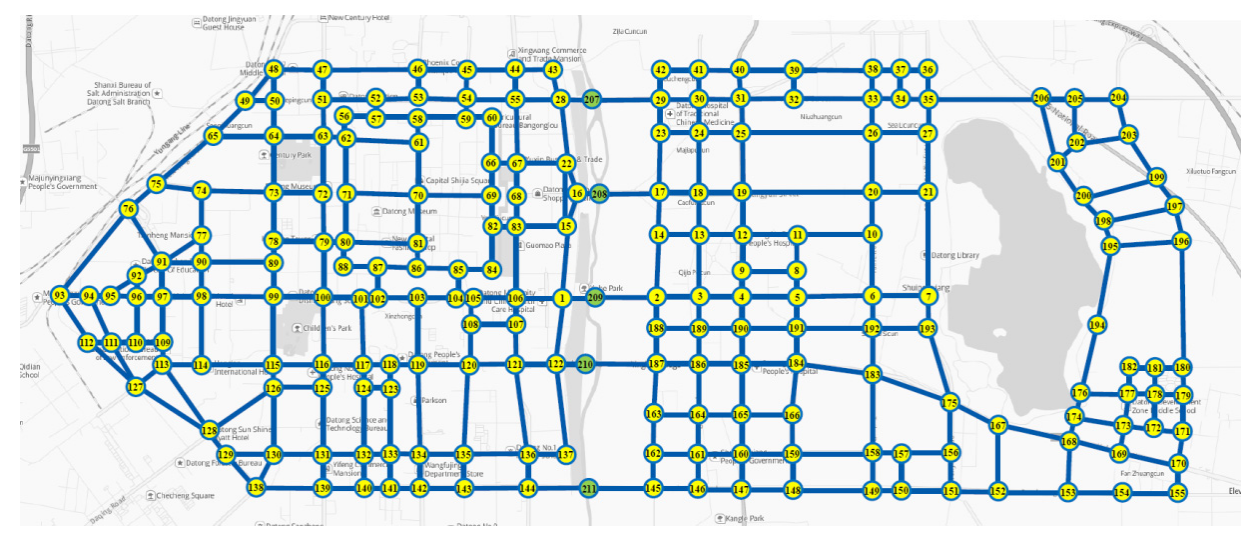

Figure 4. Network model of the urban roads in Datong, Shanxi Province, China.

Table 3. Characteristics of the road network in Datong.

\begin{tabular}{cc}
\hline Characteristic & Value \\
\hline Number of nodes & 211 \\
Number of edges & 348 \\
Average degree & 3.2398 \\
Standard deviation of degree & 0.6752 \\
Average length of edges $(\mathrm{km})$ & 0.5235 \\
Standard deviation of the edge length $(\mathrm{km})$ & 0.2221 \\
Network diameter $(\mathrm{km})$ & 15.1240 \\
\hline
\end{tabular}

Table 4. Classification of the bridges in Datong.

\begin{tabular}{cccc}
\hline Node Number & Bridge Name & Span & $\begin{array}{c}\text { Hazus Bridge } \\
\text { Classification }\end{array}$ \\
\hline 207 & Pingcheng Bridge & 21 & HWB11 \\
208 & Xingyun Bridge & 26 & HWB11 \\
209 & Beidu Bridge & 5 & HWB3 \\
210 & Yingbin Bridge & 22 & HWB19 \\
211 & Nanhuan Bridge & 12 & HWB19 \\
\hline
\end{tabular}

\subsection{Seismic Damage Simulation}

For generating spatially variable seismic ground motions, the EPSD model proposed by Wang et al. [28] and the coherency function model proposed by Wang et al. [29] are used in the spectral representation method. In this article, the earthquake intensity is average peak ground acceleration (PGA) of the urban area. For evaluating the vulnerability of the road network, the ground motions with different intensities are required. The average PGAs of the samples of spatially variable seismic ground motions will be modified to the designed values. The samples of the ground motions at the positions of the edges and nodes are simulated by Equation (1). Figures 5 and 6 show the artificial ground motions at the node 209 and the edges $1-15$ for average PGA $=0.3$ and $0.5 \mathrm{~g}$. It should be noted that the PGA of each ground motion sample may not equal the average PGA because of the spatial variation effect of seismic ground motions. The average PGA is just the measure of the earthquake intensity for the whole urban area. The PGAs for the nodes and edges should be calculated from the samples of the spatially variable ground motions. 


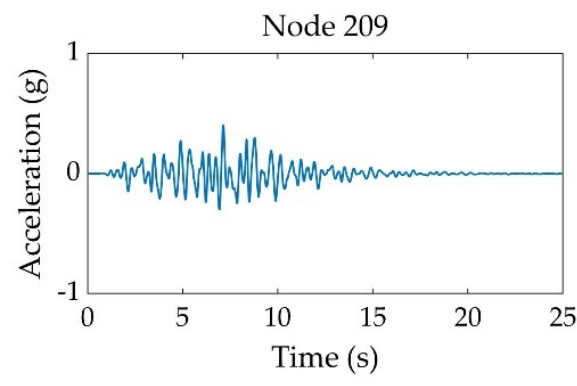

(a)

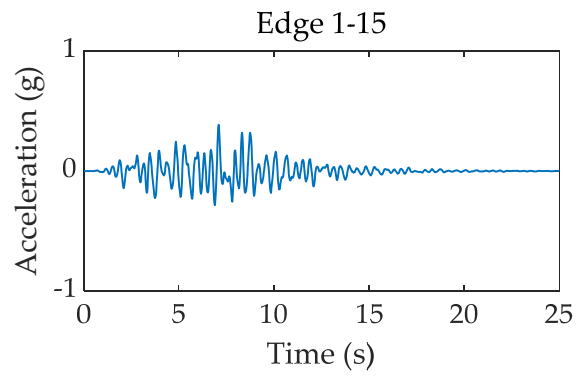

(b)

Figure 5. Ground motion samples at (a) node 209 and (b) edges 1-15 for PGA $=0.3 \mathrm{~g}$.

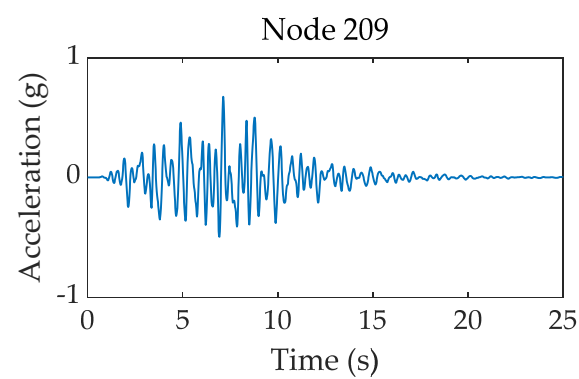

(a)

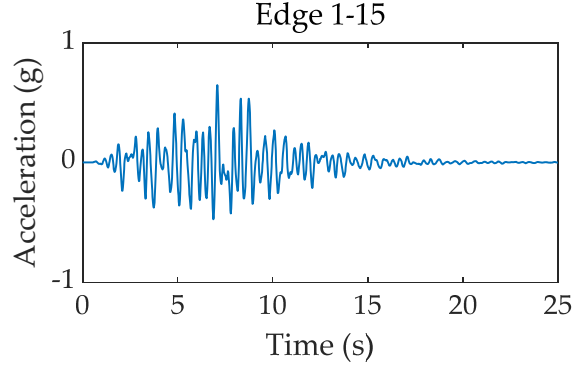

(b)

Figure 6. Ground motion samples at (a) node 209 and (b) edges 1-15 for PGA $=0.5 \mathrm{~g}$.

After determining the PGAs, the damage probabilities of the nodes and edges should be calculated. The damage of the intersections is not considered here. The probability of the structural damage of the bridges could be calculated from the bridge fragility curves in the Hazus program [38]. For road sections, an empirical fragility function which is proposed from the hazard investigation of the 2008 Wenchuan earthquake, China [7], is used here. This empirical fragility function gives the blockage probability of a road section with a length of $1 \mathrm{~km}$. Under the assumption that the building collapse is independent along the road section, the blockage probability of the road section of length $L \mathrm{~km}$ can be expressed as:

$$
P_{f, i j}=1-[1-F(\mathrm{PGA})]^{L}
$$

in which $F($ PGA) is the fragility function of the road of per unit length. Figure 7 shows the blockage probability of per unit length of road section represented by a solid line. For presenting the influence of the length on the blockage probability of a road section, the blockage probabilities of the road sections with lengths of, respectively, $0.25,0.5,0.75$, and $1.5 \mathrm{~km}$ under different PGAs are also shown by the dotted lines in Figure 7. It should be noted that the fragility function in Reference [7] considers not only the building collapse debris but also the structural damage of embankments, slopes, and retaining walls. This fragility function is applicable to the cities in mountain areas but may overestimate the blockage probability of road sections in plain areas.

As described above, the Monte Carlo method is used to simulate the random damage of the urban road network and evaluate the seismic vulnerability. The typical samples of the post-earthquake road network are shown in Figure 8 when the average PGA equals $0.3,0.4,0.5$, and $0.6 \mathrm{~g}$ respectively. The four performance indexes for each sample are also calculated to determine its damage state. The dotted lines and nodes represent that the corresponding road sections and bridges are impassable after the earthquake. Intuitively, the number of the damaged road sections and components increases with the increasing earthquake intensity. 


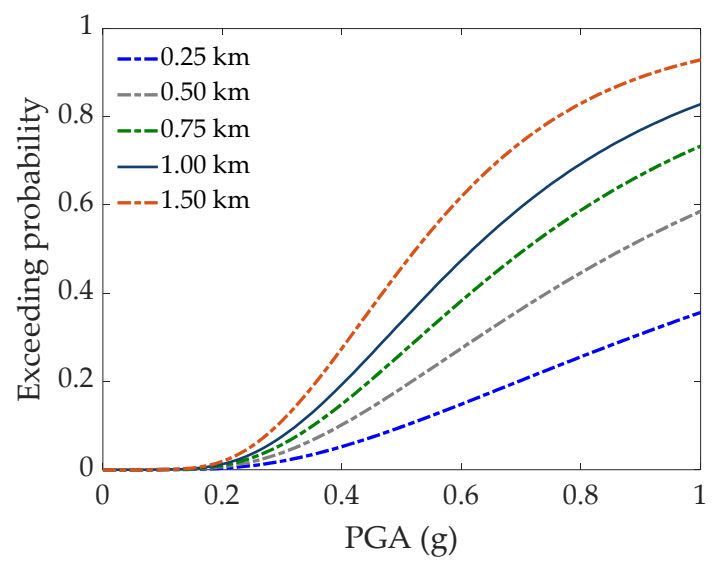

Figure 7. Fragility curves of the road sections with the lengths of $0.25,0.5,0.75,1.0$, and $1.5 \mathrm{~km}$.

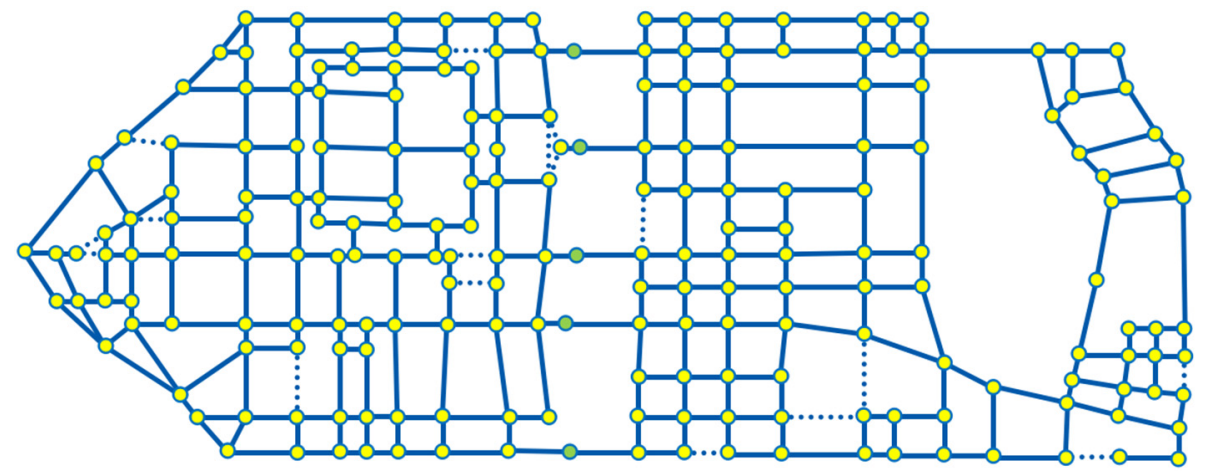

(a)

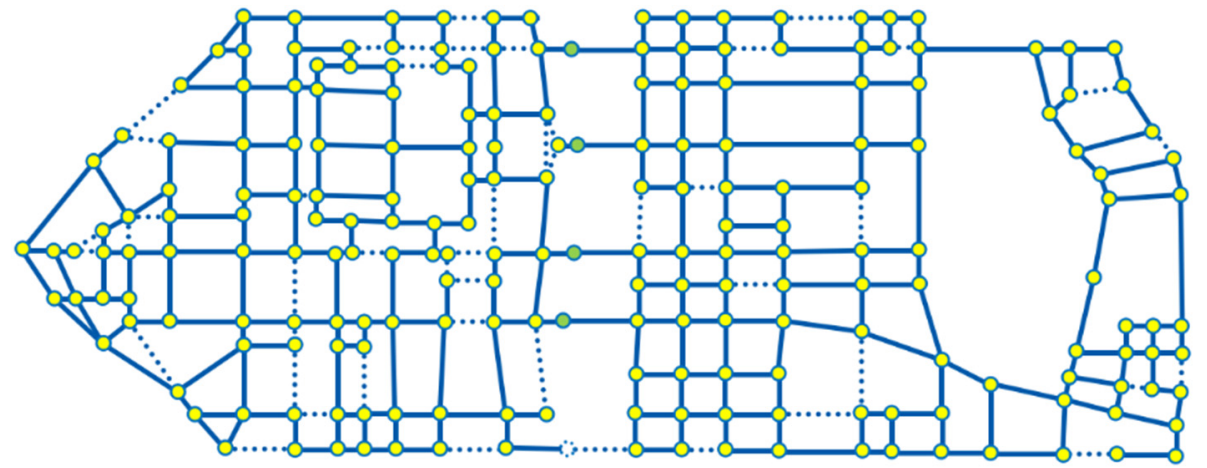

(b)

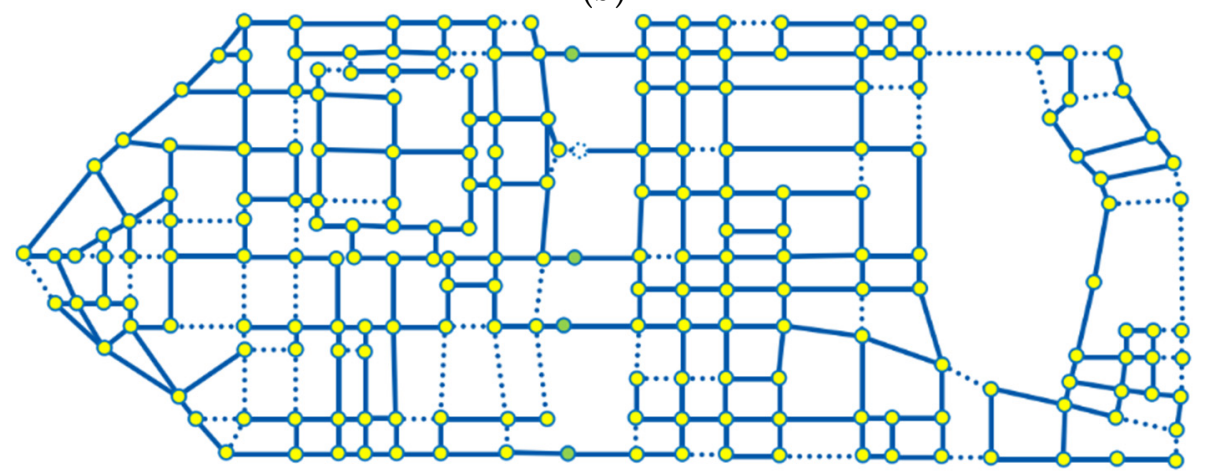

(c)

Figure 8. Cont. 


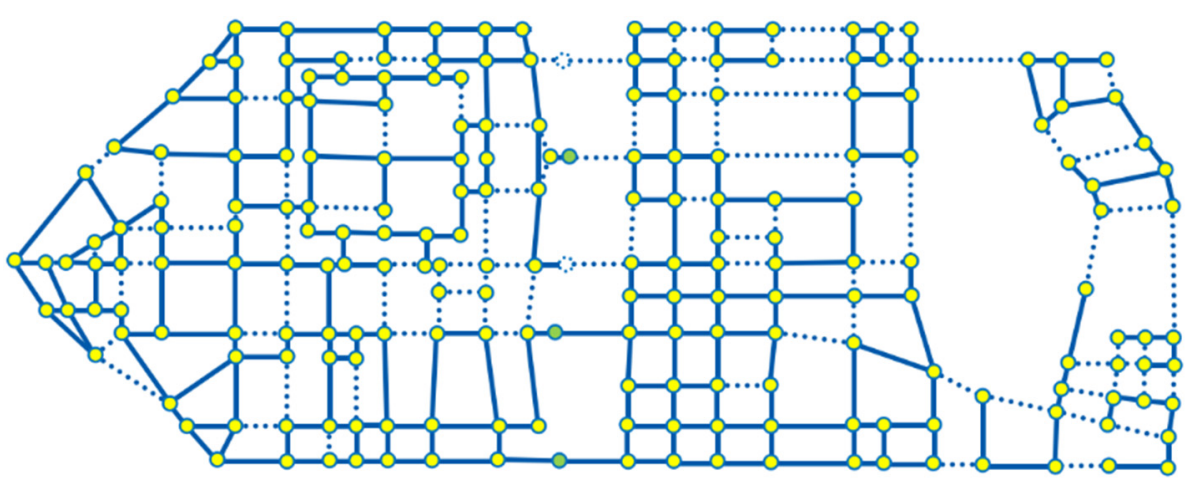

(d)

Figure 8. Samples of the post-earthquake road networks for different earthquake intensities. (a) Average PGA $=0.3 \mathrm{~g},=0.048, N_{C}=1, \rho_{C N}=1$ and $\rho_{C D}=1.049$; (b) Average PGA $=0.4 \mathrm{~g}$, $\rho_{E}=0.126, N_{C}=1, \rho_{C N}=1$ and $\rho_{C D}=1.153$; (c) Average PGA $=0.5 \mathrm{~g}, \rho_{E}=0.184, N_{C}=5, \rho_{C N}=0.973$ and $\rho_{C D}=1.272 ;(d)$ Average PGA $=0.6 \mathrm{~g}, \rho_{E}=0.258, N_{C}=13, \rho_{C N}=0.805$ and $\rho_{C D}=1.363$.

The damage simulation shows that, when the average PGA equals $0.3 \mathrm{~g}$, only a small number of edges are damaged, and the entire road network is not significantly affected. When the average PGA equals $0.4 \mathrm{~g}$, more edges are damaged, but the road network is connected. When the average PGA increases to $0.5 \mathrm{~g}$, the connectivity of the network is lost, but there is still a large piece that connects $97.3 \%$ of the nodes. When the average PGA reaches $0.6 \mathrm{~g}$, the number of the pieces in the post-earthquake road network increases and the road network begins to be fragmented. For this earthquake intensity, two bridges are also damaged. Figures 9-12, respectively, present the distribution of the four performance indexes of 1000 samples for different earthquake intensities.
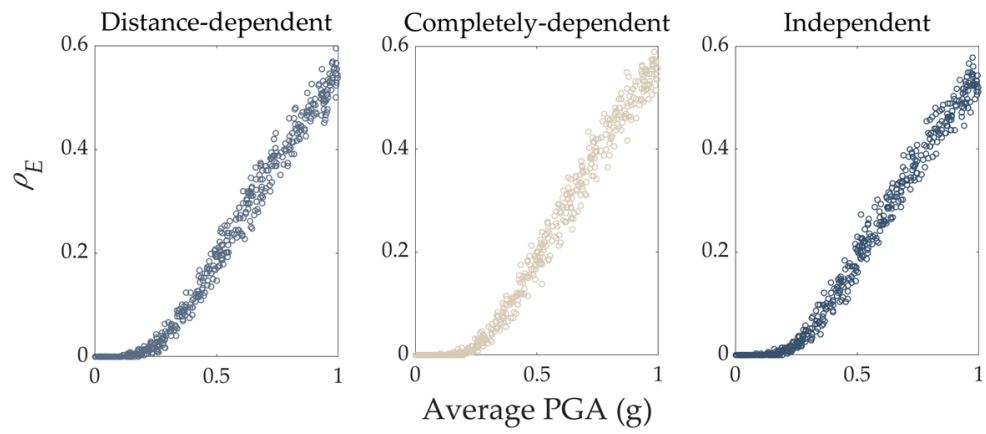

Figure 9. The relationship between $\rho_{E}$ and the average PGA.
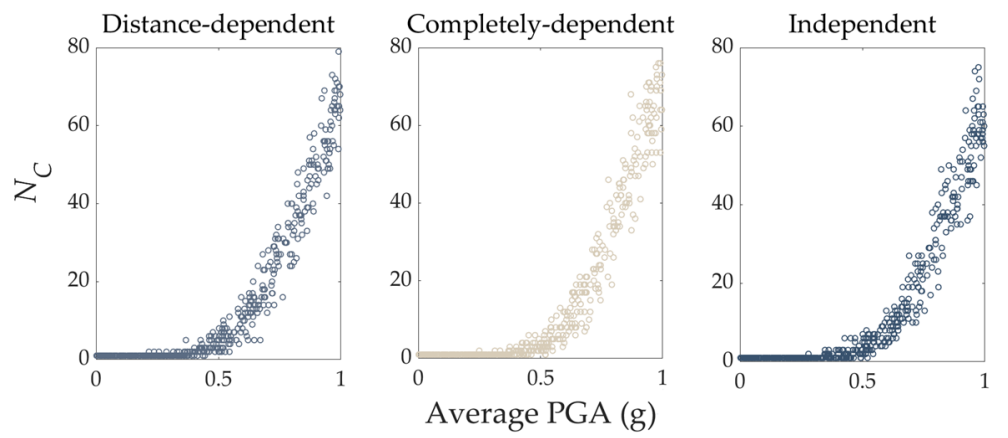

Figure 10. The relationship between $N_{C}$ and the average PGA. 

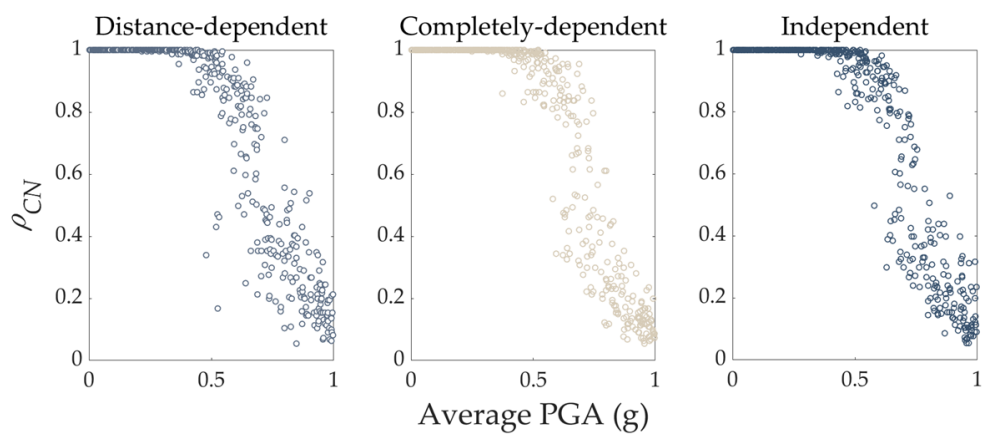

Figure 11. The relationship between $\rho_{C N}$ and the average PGA.
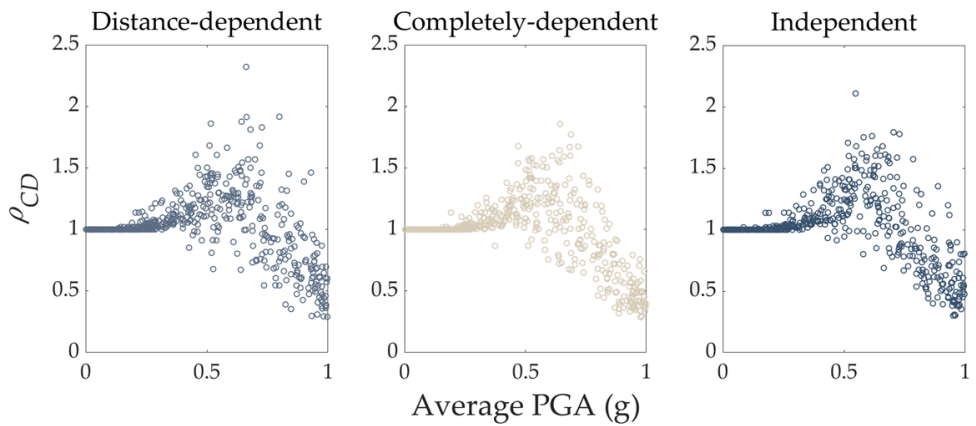

Figure 12. The relationship between $\rho_{C D}$ and the average PGA.

Besides the spatially variable ground motions, two other groups of seismic ground motions, the intensities of which are respectively identical and completely random, are also considered for comparison. The performance indexes obtained from these two groups of ground motions are also shown in Figures 9-12. Here, the legends 'distance-dependent', 'completely-dependent', and 'independent', respectively, denote the results obtained by the ground motions with spatially variable, identical, and completely random PGAs. It could be found that, when the average PGA is less than $0.2 \mathrm{~g}, N_{C}$ and $\rho_{C N}$ both equal 1 , which means that the road network does not lose its connectivity at this earthquake intensity level. When the average PGA is larger than $0.2 \mathrm{~g}$, some road network samples are disconnected. The peak value of $\rho_{C D}$ appears when the average PGA is $0.6 \mathrm{~g}$. This phenomenon indicates that if the average PGA is larger than $0.6 \mathrm{~g}$ the road network will be fragmented and lose its transport capacity completely.

It should be noted that the completely dependent ground motions are identical and do not consider the spatial variation effect. In this situation, the damage simulation of road network here is consistent with other available random methods, for example, the method in Reference [18].

\subsection{Analysis of the Effect of Spatially Variable Ground Motions}

For analyzing the effect of the spatial variation of seismic ground motions on the vulnerability of the urban road network in Datong, eight earthquake intensities, the average PGAs of which are $0.10,0.15,0.20,0.25,0.30,0.40,0.50$, and $0.60 \mathrm{~g}$, are considered to simulate the damage of the road network. For each earthquake intensity, 1000 samples of the post-earthquake road network are simulated. The four performance indexes of the samples are all calculated, and their damage states are determined according to Table 2. The distributions of the damage states of the post-earthquake road network for different average PGAs are shown in Figure 13. 


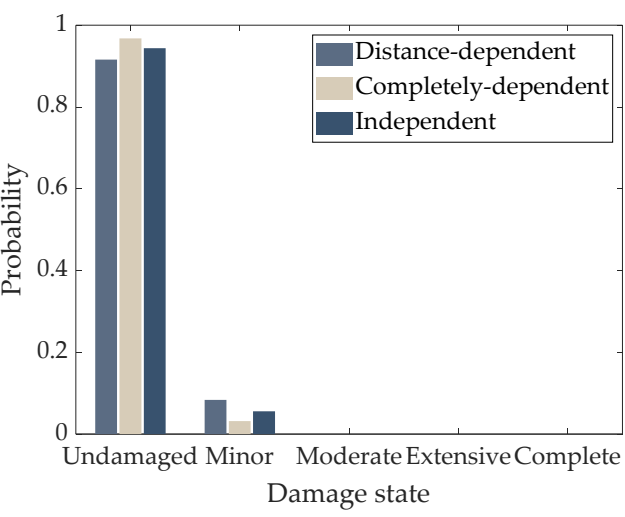

(a)

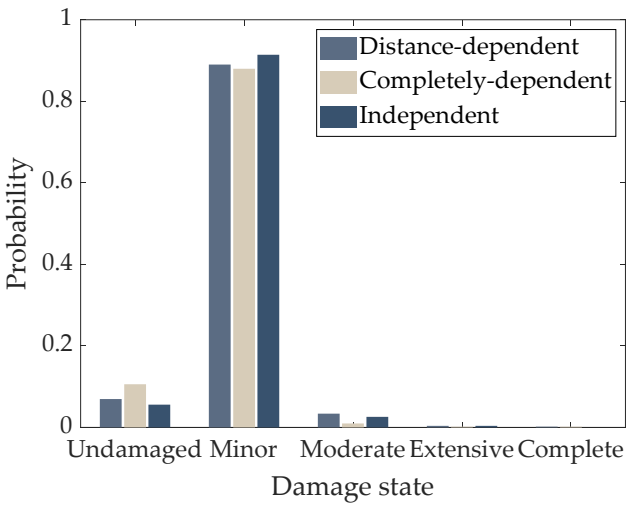

(c)

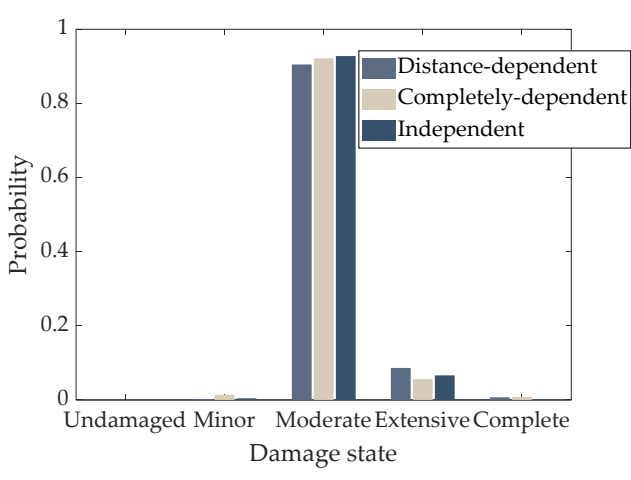

(e)

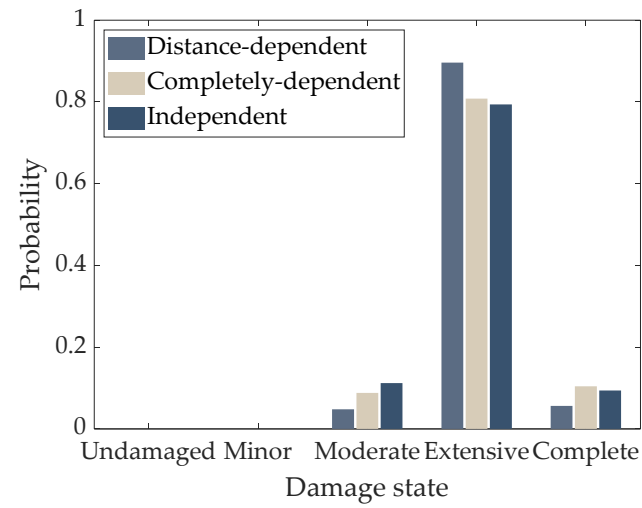

(g)

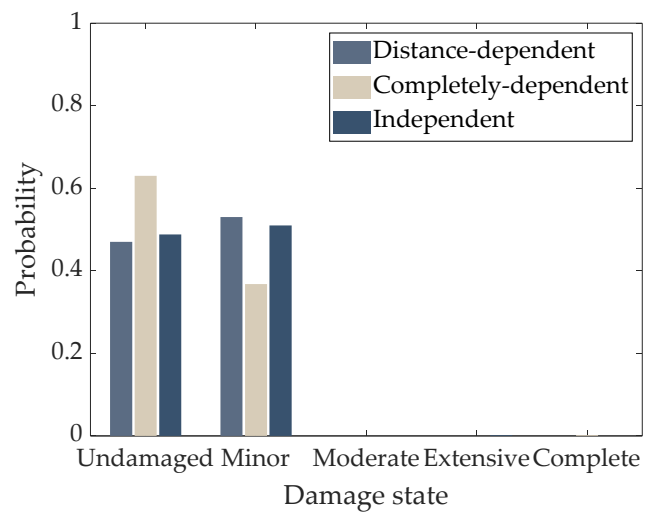

(b)

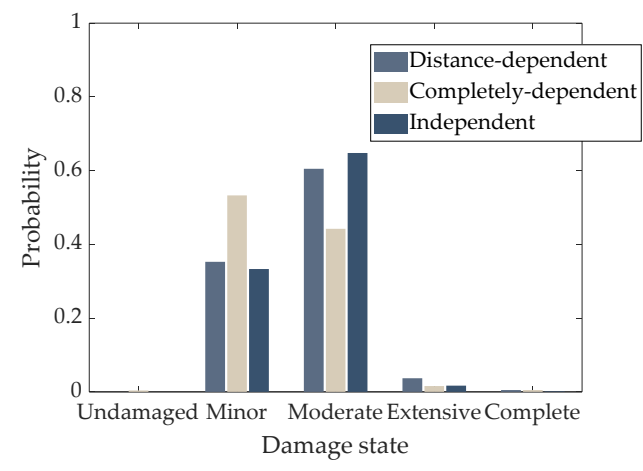

(d)

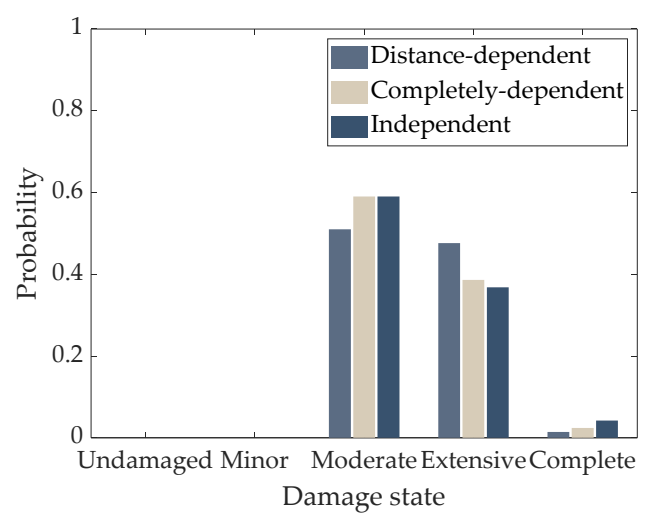

(f)

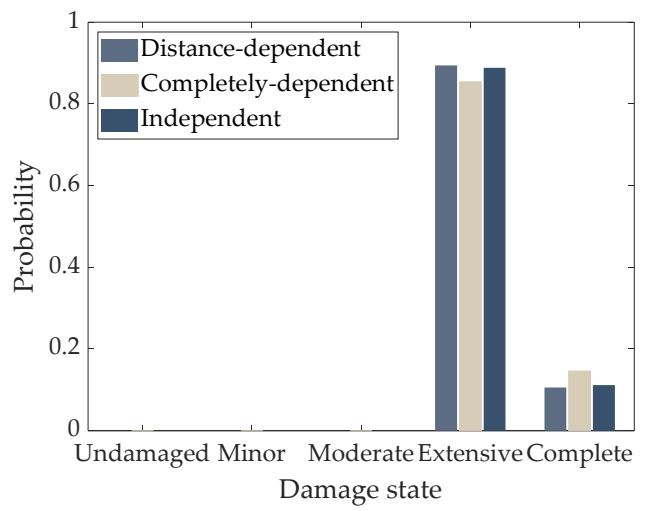

(h)

Figure 13. Occurrence probability of different damage states of the post-earthquake road network with the average PGA equaling (a) 0.10, (b) 0.15, (c) 0.20, (d) 0.25, (e) 0.30, (f) 0.40, (g) 0.50, and (h) $0.60 \mathrm{~g}$. 
It could be found that when the average PGA equals 0.15 in Figure $13 \mathrm{~b}$, the usage of the ground motions with identical earthquake intensity will overestimate the occurrence probability of the undamaged state and, as a result, underestimate the possibility of the occurrence of the minor damage. A similar phenomenon also appears for the average PGA equaling $0.25 \mathrm{~g}$ in Figure $13 \mathrm{~d}$. This phenomenon indicates that using consistent earthquake excitation will underestimate the seismic risk of an urban road network.

When the average PGA equals 0.4 and $0.5 \mathrm{~g}$, the occurrence probability of the extensive damage state obtained by the spatially variable ground motions is higher than those obtained by the other two types of earthquake excitations. This phenomenon indicates that using consistent or completely random ground motions will underestimate the seismic risk when the average PGA is close to $0.5 \mathrm{~g}$. Thus, the simulation results suggest that the spatial variation of seismic ground motions must be considered in the vulnerability analysis of urban road networks.

\section{Concluding Remarks}

This article developed a method to evaluate the seismic vulnerability of the urban road network and analyzed the effect of the spatial variation of seismic ground motions. The conclusions of this study include:

(1) A framework to simulate the seismic damage and evaluate the vulnerability of the urban road network is presented. The urban road infrastructure system is modeled as a spatial network. The spatially variable seismic ground motions are generated by the spectral representation method. The structural damage of the vulnerable road components, especially the bridges, and the blockage of road sections due to the building collapse debris are all considered and treated as random accidents. Five damage states are defined to reflect the performance of the post-earthquake road network. Four performance indexes of the post-earthquake road network are introduced to measure its damage state.

(2) The case study on Datong, Shanxi Province, China, indicates that the usage of the identical or complete random earthquake excitation will underestimate the damage state of the post-earthquake road network. The spatial variation of seismic ground motions must be considered in the vulnerability analysis of urban road networks.

The future developments of this study include the consideration of the difference in the building environment of the road sections and the expansion of the proposed method to analyze the seismic vulnerability of other lifeline systems.

Author Contributions: Conceptualization, D.W.; methodology, D.W. and Y.L.; formal analysis, D.W., X.Z. and Y.L.; writing, Y.L. and X.Z.; visualization, Y.L. All authors have read and agreed to the published version of the manuscript.

Funding: This research was funded by Natural Science Foundation of Hebei Province (E2020203103) and Science and Technology Project of Hebei Education Department (BJ2019030).

Data Availability Statement: The data presented in this study are available on request from the corresponding author.

Conflicts of Interest: The authors declare no conflict of interest.

$\begin{array}{ll}\text { Abbreviations } \\ m & \text { Number of the ground motions } \\ N_{f} & \text { Number of the frequency components } \\ \Delta \omega & \text { Frequency bandwidth } \\ \omega_{c} & \text { Upper cut-off frequency } \\ H_{j r}\left(\omega_{s}, t\right) & \text { Elements of the Cholesky decomposition of the EPSD matrix } \\ \vartheta_{j r}(\omega, t) & \text { Phase angle of } H_{j r}\left(\omega_{s}, t\right)\end{array}$




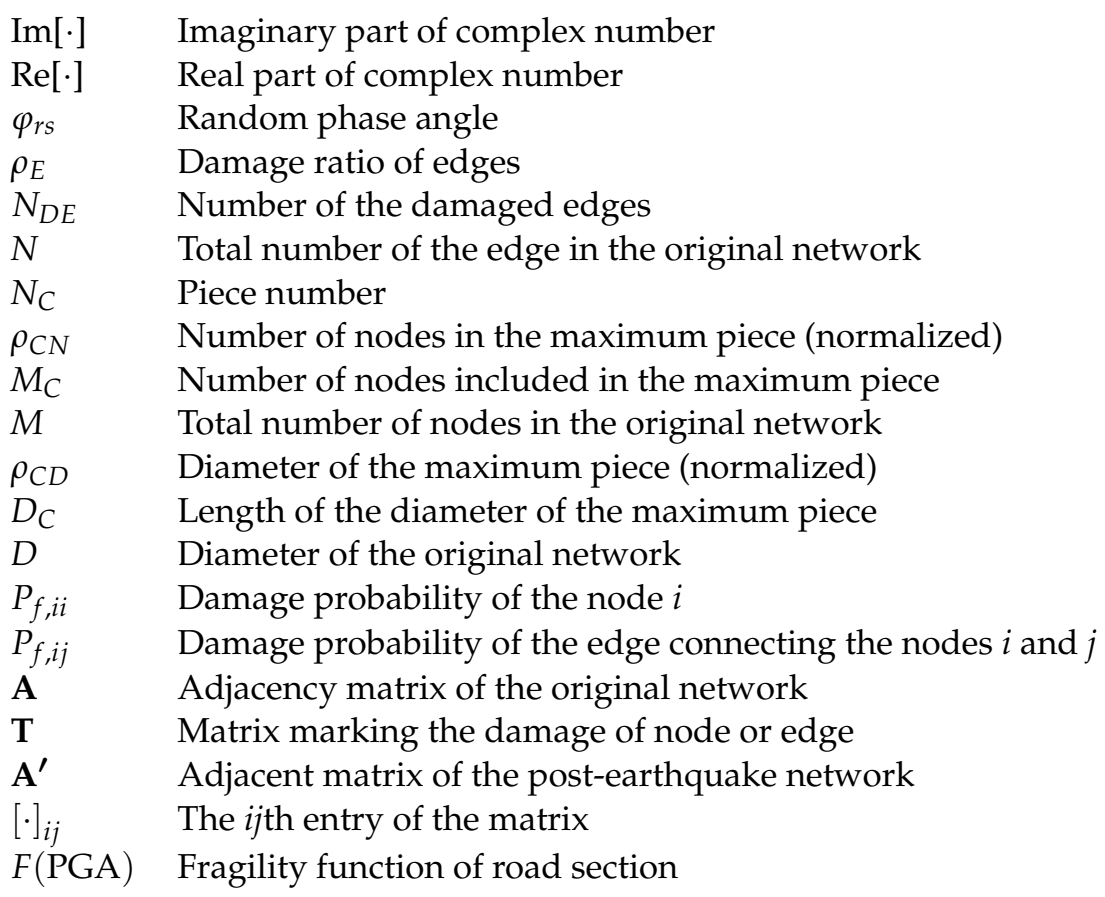

\section{References}

1. Ballantyne, D. Sri Lanka lifelines after the December 2004 great Sumatra earthquake and tsunami. Earthq. Spectra 2006, 22 (Suppl. S3), 545-559. [CrossRef]

2. Hu, Y.X.; Liu, X.R.; Jiang, Y. Overviews of failure mode and reconstruction of road traffic facilities in Wenchuan earthquakestricken areas. Procedia Environ. Sci. 2012, 12, 615-627. [CrossRef]

3. Martínez, A.; Hube, M.A.; Rollins, K.M. Analytical fragility curves for non-skewed highway bridges in Chile. Eng. Struct. 2017, 141, 530-542. [CrossRef]

4. Alam, M.I.; Kim, D. Spatially varying ground motion effects on seismic response of adjacent structures considering soil-structure interaction. Adv. Struct. Eng. 2014, 17, 131-142. [CrossRef]

5. Lagaros, N.D.; Tsompanakis, Y.; Psarropoulos, P.N.; Georgopoulos, E.C. Computationally efficient seismic fragility analysis of geostructures. Comput. Struct. 2009, 87, 1195-1203. [CrossRef]

6. Maruyama, Y.; Yamazaki, F.; Mizuno, K.; Tsuchiya, Y.; Yogai, H. Fragility curves for expressway embankments based on damage datasets after recent earthquakes in Japan. Soil Dyn. Earthq. Eng. 2011, 30, 1158-1167. [CrossRef]

7. Liao, Y. Investigation and Analysis of Highway Subgrade Seismic Damage and Vulnerability in Wenchuan Earthquake. Master's Thesis, Southwest Jiaotong University, Chengdu, China, 2012. (In Chinese).

8. Argyroudis, S.; Kaynia, A.M. Analytical seismic fragility functions for highway and railway embankments and cuts. Earthq. Eng. Struct. Dyn. 2015, 44, 1863-1879. [CrossRef]

9. Goretti, A.; Sarli, V. Road network and damaged buildings in urban areas: Short and long-term interaction. Bull. Earthq. Eng. 2006, 4, 159-175. [CrossRef]

10. Harirchian, E.; Hosseini, S.E.A.H.; Jadhav, K.; Kumari, V.; Rasulzade, S.; Isik, E.; Wasif, M.; Lahmer, T. A review on application of soft computing techniques for the rapid visual safety evaluation and damage classification of existing buildings. J. Build. Eng. 2021, 43, 102536. [CrossRef]

11. Alam, N.; Alam, M.S.; Tesfamariam, S. Buildings' seismic vulnerability assessment methods: A comparative study. Nat. Hazards 2012, 62, 405-424. [CrossRef]

12. Argyroudis, S.; Selva, J.; Gehl, P.; Pitilakis, K. Systemic seismic risk assessment of road networks considering interactions with the built environment. Comput. Aided Civ. Infrastruct. Eng. 2015, 30, 524-540. [CrossRef]

13. Zanini, M.A.; Faleschini, F.; Zampieri, P.; Pellegrino, C.; Gecchele, G.; Gastaldi, M.; Rossi, R. Post-quake urban road network functionality assessment for seismic emergency management in historical centres. Struct. Infrastruct. Eng. 2017, 13, 1117-1129. [CrossRef]

14. Aydin, N.Y.; Duzgun, H.S.; Wenzel, F.; Heinimann, H.R. Integration of stress testing with graph theory to assess the resilience of urban road networks under seismic hazards. Nat. Hazards 2018, 91, 37-68. [CrossRef]

15. Capacci, L.; Biondini, F.; Titi, A. Lifetime seismic resilience of aging bridges and road networks. Struct. Infrastruct. Eng. 2020, 16, 266-286. [CrossRef]

16. Zhou, Y.; Wang, J.; Sheu, J.B. On connectivity of post-earthquake road networks. Transp. Res. Part E Logist. Transp. Rev. 2019, 123, 1-16. [CrossRef] 
17. Huang, S.; Tang, Y. Assessing seismic vulnerability of urban road networks by a Bayesian network approach. Transp. Res. Part D Transp. Environ. 2019, 77, 390-402.

18. Anelli, A.; Mori, F.; Vona, M. Fragility curves of the urban road network based on the debris distributions of interfering buildings Appl. Sci. 2020, 10, 1289. [CrossRef]

19. Costa, C.; Figueiredo, R.; Silva, V.; Bazzurro, P. Application of open tools and datasets for probabilistic modeling of road traffic disruptions due to earthquake damage. Earthq. Eng. Struct. Dyn. 2020, 6, 1236-1255. [CrossRef]

20. El-Maissi, A.M.; Argyroudis, S.A.; Nazri, F.M. Seismic vulnerability assessment methodologies for roadway assets and networks: A state-of-the-art review. Sustainability 2020, 13, 61. [CrossRef]

21. Wang, D.; Wang, X.W.; Xu, J.; Feng, D.-C.; Xu, S. Framework for calculating seismic fragility function of urban road networks: A case study on Tangshan City, China. Struct. Infrastruct. Eng. 2021, 17, 1508-1522. [CrossRef]

22. Lee, R.; Kiremidjian, A.S. Uncertainty and correlation for loss assessment of spatially distributed systems. Earthq. Spectra 2007, 23, 753-770. [CrossRef]

23. Barthélemy, M. Spatial networks. Phys. Rep. 2011, 499, 1-101. [CrossRef]

24. Zerva, A. Spatial Variation of Seismic Ground Motions: Modeling and Engineering Applications; CRC Press: New York, NY, USA, 2009.

25. Samui, P.; Kim, D.; Viswanathan, R. Spatial variability of rock depth using adaptive neuro-fuzzy inference system (ANFIS) and multivariate adaptive regression spline (MARS). Environ. Earth Sci. 2015, 73, 4265-4272. [CrossRef]

26. Shinozuka, M. Simulation of multivariate and multidimensional random processes. J. Acoust. Soc. Am. 1971, 49, 357-367. [CrossRef]

27. Cacciola, P.; Deodatis, G. A method for generating fully non-stationary and spectrum-compatible ground motion vector processes Soil Dyn. Earthq. Eng. 2011, 31, 351-360. [CrossRef]

28. Wang, D.; Li, C.; Yan, C.; Xu, J.; Kong, F. An evolutionary spectrum model of nonstationary seismic ground motions considering extended source effect for engineering purposes. J. Earthq. Eng. 2020, 24, 988-1011. [CrossRef]

29. Wang, D.; Wang, L.W.; Xu, J.; Kong, F.; Wang, G.B. A directionally-dependent evolutionary lagged coherency model of nonstationary horizontal spatially variable seismic ground motions for engineering purposes. Soil Dyn. Earthq. Eng. 2019, 117, 58-71. [CrossRef]

30. Boore, D.M. Simulation of ground motion using the stochastic method. Pure Appl. Geophys. 2003, 160, 635-676. [CrossRef]

31. Conte, J.P.; Peng, B.F. Fully nonstationary analytical earthquake ground-motion model. J. Eng. Mech. 1997, 123, 15-24. [CrossRef]

32. Crempien-Laborie, J.E.; Orosco, L. An evolution ground motion model for earthquake analysis of structures in zones with little history. Soil Dyn. Earthq. Eng. 2000, 20, 373-379. [CrossRef]

33. Dabaghi, M.; Der Kiureghian, A. Stochastic model for simulation of near-fault ground motions. Earthq. Eng. Struct. Dyn. 2017, 46, 963-984. [CrossRef]

34. Der Kiureghian, A. A coherency model for spatially varying ground motion. Earthq. Eng. Struct. Dyn. 1996, 25, 99-111. [CrossRef]

35. Konakli, K.; Der Kiureghian, A.; Dreger, D. Coherency analysis of accelerograms recorded by the UPSAR array during the 2004 Parkfield earthquake. Earthq. Eng. Struct. Eng. 2014, 43, 641-659. [CrossRef]

36. Liu, T.J.; Hong, H.P. Assessment of spatial coherency using tri-directional ground motions. J. Earthq. Eng. 2016, 20, 773-794 [CrossRef]

37. Rodda, G.K.; Basu, D. Coherency model for translational and rotational ground motions. Bull. Earthq. Eng. 2018, 16, 2687-2710. [CrossRef]

38. Federal Emergency Management Agency. Hazus-MH 2.1 Technical Manual: Earthquake Model; Federal Emergency Management Agency (FEMA): Washington, DC, USA, 2010.

39. Cao, A.-T.; Tran, T.-T.; Nguyen, T.-H.-X.; Kim, D. Simplified approach for seismic risk assessment of cabinet facility in nuclear power plants based on cumulative absolute velocity. Nucl. Technol. 2020, 206, 743-757. [CrossRef]

40. Tran, T.-T.; Hussan, M.; Kim, D.; Nguyen, P.-C. Distributed plasticity approach for the nonlinear structural assessment of offshore wind turbine. Int. J. Nav. Archit. Ocean Eng. 2020, 12, 743-754. [CrossRef]

41. Tran, T.-T.; Nguyen, P.-C.; So, G.; Kim, D. Seismic behavior of steel cabinets considering nonlinear connections and site-response effects. Steel Compos. Struct. 2020, 36, 17-29. 